\title{
PENGARUH POLA KEPEMIMPINAN, MOTIVASI, DAN KOMPENSASI TERHADAP PRODUKTIVITAS KERJA KARYAWAN PT.SO GOOD FOOD BOYOLALI
}

\author{
Michel Hartanto $^{\text {() }}$, NuningLisdiana ${ }^{2)}$, Hari Purwanto ${ }^{3)}$ \\ ${ }^{1)}$ FakultasEkonomiUniversitasBoyolali \\ Universitas Boyolali, J1. Pandanaran No. 405 Boyolali
}

e-mail: micheltan9@gmail.com ${ }^{1)}$, $\underline{\text { nuninglisdiana60@email.com }}{ }^{2)}$, hariharipoer@yahoo.co.id ${ }^{3)}$

\begin{abstract}
ABSTRAK
Tujuan penelitian ini untuk menganalisa pengaruh pola kepemimpinan, motivasi, dan kompensasi terhadap produktivitas kerja karyawan PT. So Good Food Unit RTE Boyolali baik secara parsial maupun secara simultan sehingga dengan bentuk menggunakan metode kuantitatif melalui teknik pengumpulan data studi dokumen dan kuesioner terhadap 135 responden karyawan PT.So Good Food Unit RTE Boyolali.Alat analisis yang digunakan adalah beberapa uji statistic dan analisis regresi linear berganda. Dari hasil penelitian menunjukkan bahwa variabel dalam kepemimpinan motivasi serta kompensansi berpengaruh secara simultan pada karyawan PT.So Good Food Unit RTE Boyolali serta variabel motivasi secara parsial berdampak positif dan signifikan terhadap produktivitas kerja para karyawan PT. So Good Food Unit RTE Boyolali, sehingga total sumbangan pengaruh ketiga variabel tersebut sebesar $49,7 \%$.

Kata kunci : Pola kepemimpinan, motivasi, kompensasi, produktivitas
\end{abstract}

\begin{abstract}
The purpose of this study was to analyze the influence of leadership, motivation, and compensation on the work productivity of PT. So Good Food Unit RTE Boyolali. either partially or simultaneously by using quantitative methods through data collection techniques for document studies and questionnaires for 135 respondents of PT.So Good Food Unit RTEBoyolali. The analytical tools used were several statistical tests and multiple linear regression analysis. The results showed that the variables in leadership motivation and compensation had a simultaneous effect on employees of pt. so good food uniit rte boyolali and the motivation variable partially had a positive and significant impact on employee productivity of PT. So Good Food Unit RTE Boyolali, with a total contribution of the influence of the three variables of $49.7 \%$.
\end{abstract}

Keywords: leadership patterns, motivation, compensation, productivity 


\section{Pendahuluan}

Sebuah perusahaan manufaktur suatu kegiatan mengubah bahan mentah menjadi barang yang memiliki nilai jual. Salah satunya ialah PT.So Good Food Food Boyolali Unit RTE merupakan perusahaan manufaktur yang memproduksi makanan siap saji dari yang diproses dari bahan pilihan dan dioalh dengan standart mutu tinggi sehingga menghasilkan produk yang berkualitas. Sehingga untuk mencapai tujuan diperlukan pengelolaan dari berbagai macam sumber daya, salah satunya sumber daya manusia yang merupakan fungsi utama dari kegiatan organisasi yang mengelola perusahaan guna menjamin bagi perusahaan tersedianya sistim manajemen sumber daya manusia yang menjadi prinsip dasar manajemen yang mengatur hubungan peran tenaga kerja secara efektif dan efisien.

Pentingnya manajemen sumber daya manusia dikelola secara terstruktur dalam sebuah perusahaan dalam melakukan perencanaan, organisasi, pelaksanaan, serta pengawasan dengan benar menjadi tolak ukur sebuah perusahaan, disamping itu seiring meningkatnya permintaan pasar terhadap produk yang semakin meningkat produktifitas kerja sangat diperlukan karena menentukan nilai output produk yang dihasilkan perusahaan.

Peran pemimpin sangat diperlukan untuk mendapatkan target produksi sesuai permintaan pasar yang terus meningkat sehingga tujuan perusahaan akan tercapai. Seorang pemimpin atau manajer harus menerapkan pola kepemimpinan yang tepat, sesuai dengan kondisi yang sedang dihadapi agar gagasan dari kebijakan atau program kerja yang dibuat dapat diterima dan meningkatkan produktivitas sesuai dengan target perusahaan. Selain itu pemimpin juga berperan penting dalam mendorong motivasi dan semangat etos kerja karyawanya untuk mencapai produktifitas kerja berdasarkan standart operasional kerja. Selain itu Beberapa hal lain yang dapat meningkatkan motivasi karyawan dalam bekerja adalah kompensasi, yaitu dimana seseorang melakukan pekerjaan dengan harapan memperoleh kompensasi untuk memenuhi kebutuhan hidup. Perusahaan harusnya menerapkan kompensasi yang adil dan layak agar timbul kepuasan kerja karyawan sehingga diharapkan produktifitas kerja dapat meningkat.

Atas dasar latar belakang tersebut maka dirumuskan permasalahan apakah pola kepemimpinan, motivasi , dan kompensasi secara parsial berpengaruh terhadap produktivitas kerja karyawan sehingga dapat mempengaruhi terhadap hasil produksi PT.So Good Food Boyolali Unit RTE serta apakah pola kepemimpinan, motivasi dan kompensasi secara simultan berpengaruh terhadap produktivitas kerja karyawan sehingga dapat mempengaruhi terhadap hasil produksi PT.So Good Food Boyolali.

Dengan rumusan masalah seperti diatas, maka bisa di berikan penjelasan bahwa tujuan penelitian ini yang perlu dicapai yaitu agar dapat mengetahui apakah pola kepemimpinan, motivasi dan kompensasi secara parsial dan simultan dapat mempengaruhi terhadap produktivitas kerja karyawan pada PT.So Good Food Boyolali Unit RTE.

\subsection{Landasan Teori}

Menurut Flippo dalam Hasibuan (2013:11) bahwa "Manajemen Sumber Daya Manusia merupakan sistem perencanaan, pengorganisasian, pengarahan, dan pengendalian dari pengadaan, pengembangan, kompensasi, pengintegrasian, pemeliharaan, dan ketenagakerjaan, dengan maksud terwujudnya tujuan perusahaan, individu, karyawan dan masyarakat.". Menurut Samsudin (2010:22) Menyatakan "Manajemen Sumber Daya Manusia merupakan suatu kegiatan pengelolaan yang meliputi pendayagunaan, pengembangan, penilaian, pemberian balas jasa bagi manusia sebagai individu anggota organisasi atau perusahaan bisnis." Sehingga manajemen sumber daya manusia sebagai merupakan unsur penggerak utama dalam suatu organisasi.

\subsection{Kepemimpinan}

Menurut Hasibuan (2011:157) menyatakan bahwa "kepemimpinan seseorang yang mempergunakan wewenang dan kepemimpinannya untuk mengarahkan orang lain serta bertanggung jawab atas pekerjaan orang tersebut dalam mencapai suatu tujuan. "Pola kepemimpinan juga merupakan kemampuan seseorang untuk mengarahkan orang lain yang terorganisir dan teratur sesuai dengan fungsi ketetapan demi tercapainya tujuan organisasi. 


\subsection{Motivasi}

Menurut Richard M. Stears dikutip Sedarmayanti ( 2009 : 233 ) bahwa "motivasi merupakan kekuatan kecenderungan seorang individu melibatkan diri dalam kegiatan yang berarahkan sasaran dalam pekerjaan." Sedangkan Menurut Samsudin (2010:281) mengemukakan bahwa "motivasi merupakan proses mempengaruhi atau mendorong dari luar terhadap seseorang atau kelompok kerja agar mereka mau melaksanakan sesuatu yang telah ditetapkan.'Dari beberapa pendapat parah ahli ini dapat di simpulkan bahwa esensi dari motivasi yaitu mampu untuk menggerakan dan menciptakan sebuah semangat nyata serta perilaku kerja agar dapat memberikan kontribusi luar biasa pada organisasi maupun perusahaan dalam mencapai tujuannya.

\subsection{Kompensasi}

Dalam bukunya Pengembangan Sumber Daya Manusia menurut Notoatmodjo (2009:142) menyatakan bahwa "kompensasi adalah segala sesuatu yang diterima oleh karyawan sebagai balas jasa untuk kerja atau pengabdian mereka. Faktor-faktor yang mempengaruhi kompensasi adalah produktivitas, kemampuan untuk membayar, kesediaan untuk membayar, suplai dan permintaan tenaga kerja, organisasi karyawan dan peraturan dan perundang-undangan dalam suatu wilayah.”

\subsection{Produktivitas}

Produktivitas digunakan sebagai tolak ukur dalam kegiatan produksi, dengan perbandingan antara keluaran (output) dengan masukan (input). Semakin tinggi keluaran yang dihasilkan maka tingkat keberhasilan perbandingan akan semakin tinggi. Produktivitas ini dapat berupa sumber daya manusia atau tenaga kerja. Bisa kemudian kita ungkapkan semakin banyak produktivitas maka akan lebih muda untuk melakukan pekerjaan dengan waktu yang singkat tetapi dengan jumlah sumber daya manusia yang sedikit dan tidak mengorbangkan sebuah kualitas.

Menurut Siagian (2009:24) Produktivitas kerja adalah "kemampuan memperoleh manfaat sebesar-besarnya dari sarana dan prasarana yang tersedia dengan menghasilkan (output) yang optimal bahkan kalau mungkin yang maksimal. Produktivitas merupakan kombinasi dari kemampuan, usaha,dan kesempatan yang dapat dinilai dari hasil kerjanya."

\subsection{PengembanganHipotesis}

Dengan berdasarakan sebuah teori dan konsep pada penelitian ini yang di jabarkan secara rinci maka peneliti memiliki tujuan untuk mengukur sejauh mana pengaruhnya pada produktivitas kerja. Adapun hasilnya bisa di lihat pada bagan di bawah ini:

\section{Gambar 1}

KerangkaPikiran

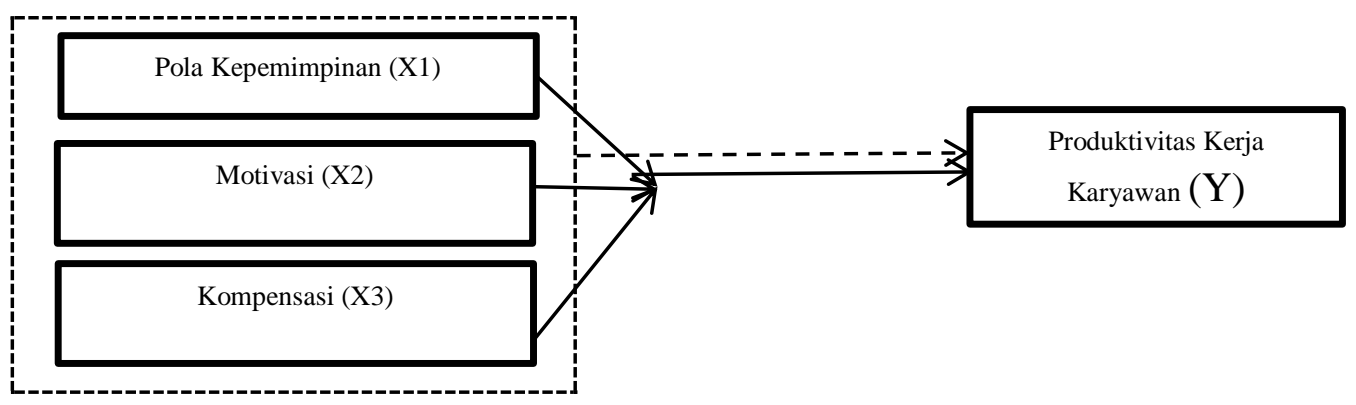

H1 : Pola kepemimpinan, Motivasi, dan kompensasi secara parsial berpengaruh signifikan terhadap produktivitas karyawan PT.So Good Food Boyolali

H2 : Pola kepemimpinan, Motivasi, dan kompensasi secara simultan berpengaruh signifikan terhadap produktivitas karyawan PT.So Good Food Boyolali 


\subsection{Metode Penelitian}

Penelitian ini menggunakan metode analisis deskriptif dengan pendekatan kuantitatif menekankan analisisnya pada data-data (angka-angka) yang diolah dengan metode statistik.Pendekatan kuantitatif menekankan pada analisis proses berfikir secara deduktif serta induktif yang berkaitan dengan dinamika hubungan antar fenomena yang diamati. Sedangkan penelitian deskriptif merupakan penelitian yang bertujuan untuk memperoleh ciri variabel dengan sifat verifikatif yang pada dasarnya menguji kebenaran dari suatu hipotesis dengan pengumpulan data di lapangan untuk mengetahui apakah pola kepemimpinan, motivasi, dan kompensasi secara parsial dan simultan berpengaruh terhadap produktivitas kerja karyawan PT. So Good Food unit RTE di Boyolali. Teknik pengumpulan data yang digunakan dalam penelitian ini kuesioner dengan 135 responden di lapangan menggunakan teknik probability sampling dan jenis simple random sampling.

Analisis data yang dilakukan dengan teknik statistika deskriptif serta uji validitas dan reliabilitas data penelitian, regresi linear berganda dengan tahap analisis normalitas data, analisis deskriptif, korelasi dan koefesien determinasi serta uji hipotesis dengan menggunakan program SPSS 22 .

\subsection{Hasil Dan Pembahasan}

Adapun hasil yang di capai melalui deskriptif berdasarkan tanggapan responden diperoleh pada

Tabel 4.1

\section{StatistikDeskriptif( Y )}

\begin{tabular}{|c|c|c|c|c|c|}
\hline & $\mathrm{N}$ & Min & Max & Mean & Deviation \\
\hline $\begin{array}{l}\text { POLA } \\
\text { KEPEMIMPIN } \\
\text { AN } \\
\text { MOTIVASI } \\
\text { KOMPENSASI } \\
\text { PRODUKTIFIT } \\
\text { AS } \\
\text { Valid } \\
\text { (listwise) }\end{array}$ & $\begin{array}{l}135 \\
135 \\
135 \\
135\end{array}$ & $\begin{array}{r}33 \\
30 \\
36,00\end{array}$ & $\begin{array}{r}50 \\
50 \\
50,00\end{array}$ & $\begin{array}{r}43,78 \\
43,19 \\
43,24 \\
44,71 \\
85\end{array}$ & $\begin{array}{r}3,771 \\
3,267 \\
4,040 \\
3,37164\end{array}$ \\
\hline
\end{tabular}

Dengan melihat tabel 4.1 diatas menunjukan bahwa jumlah data " $\mathrm{N}$ " setiap variabel yang valid berjumlah 135, dengan sampel pola kepemimpinan (X1) nilai minimum 33, maximum 50, dan mean 43,78 diperoleh standar deviasi sebesar 3,771 dengan nilai mean lebih besar dari nilai standar sehingga penyimpangan data yang terjadi rendah maka penyebaranya merata, sampel motivasi (X3) nilai minimum 33, maximum 50, dan mean 43,19 di peroleh standar deviasinya sebesar 3,267 yang berarti nilai mean lebih besar dibandingkan dengan nilai standar sehingga penyimpangan data yang terjad irendah maka penyebaranya merata, sampel kompensasi (X3) diperoleh nilai minimum 36, maximum 50, dan mean 44,71 diperoleh standar deviasi sebesar 3,371 artinya nilai mean lebih besar dari nilai standar sehingga penyimpangan data yang terjadi rendah maka penyebaranya merata, serta data produktivitas kerja (Y) dengan nilai minimum 33, maximum 50, dan mean 43,78 diperoleh standar deviasi sebesar 3,771 yaitu pencerminan penyimpangan tinggi dengan nilai mean lebih besar dari nilai standar deviasi sehingga mengindikasi bahwa penyebaran data menunjukan hasil yang normal dan merata.

Hasil perhitungan uji validitas seluruh variabel penelitian yang pola kepemimpinannya menghasilkan sebuah butir pernyataan di sebutkan valid karena $r_{\text {hitung pola pernyataan pola }}$ kepemimpinan memperoleh nilai tertinggi 0,811 , motivasi nilai tertinggi 0,793 , kompensasi nilai tertinggi 0,853, dan produktivitas kerja memperoleh nilai tertinggi sebesar 0,792 artinya lebih besar dari $\mathrm{r}_{\text {table }}$ dengan signifikansi $(\alpha)$ 5\% senilai 0,169 Maka semua elemen tersebut dinyatakan valid. Beserta hasil uji reliabilitas terhadap pola kepemimpinan $\left(\mathrm{X}_{1}\right)$, motivasi $\left(\mathrm{X}_{2}\right)$, kompensasi $\left(\mathrm{X}_{3}\right)$, dan produktivitas 
kerja (Y), dapat di peroleh koefisien reabilitasss senilai $0,889\left(\mathrm{X}_{1}\right), 0,848\left(\mathrm{X}_{2}\right), 0,905\left(\mathrm{X}_{3}\right)$ dan $0,843(\mathrm{Y})$. Nilai tersebut lebih besar dari 0,600 batas nilai sedang, sehingga seluruh pernyataan dinyatakan reliable.

Tabel 4.2

Uji Normalitas

\begin{tabular}{|c|c|c|}
\hline & & $\begin{array}{l}\text { Unstandardiz } \\
\text { ed Residual }\end{array}$ \\
\hline $\begin{array}{l}\text { N } \\
\text { Normal Parameters a,b } \\
\text { "Most Extreme } \\
\text { Differences", } \\
\text { Test Statistic } \\
\text { Asymp. Sig. (2-tailed) }\end{array}$ & $\begin{array}{l}\text { Mean } \\
\text { Std. } \\
\text { Deviation } \\
\text { Absolute } \\
\text { Positive } \\
\text { Negative }\end{array}$ & $\begin{array}{r}\text { “135" } \\
, 0000000 \\
“ 2,39034302 \\
, \\
, 065 \\
, 035 \\
-, 065 \\
, 065 \\
, 200^{\mathrm{c}, \mathrm{d}}\end{array}$ \\
\hline
\end{tabular}
a. Test distribution is Normal.
b. Calculated from data.
c. Lilliefors Significance Correction.
d. This is a lower bound of the true significance.

Berdasarkan nilai Test Statistic Kolmogorov Smirnov dari tabel 4.2 yaitu 0,065 dan signifikan pada 0,200 yakni> 0,05 ini berarti bahwa distribusi data Produktivitas kerja adalah berdistribusi normal.

Tabel 4.3

Hasil Uji - t

"Coefficients"

\begin{tabular}{|c|c|c|c|c|c|c|}
\hline \multirow{2}{*}{\multicolumn{2}{|c|}{ Model }} & \multicolumn{2}{|c|}{$\begin{array}{c}\text { Unstandardized } \\
\text { Coefficient }\end{array}$} & \multirow{2}{*}{\begin{tabular}{|c|}
$\begin{array}{c}\text { Standardize } \\
\mathrm{d} \\
\text { Coefficient }\end{array}$ \\
Beta \\
\end{tabular}} & \multirow[b]{2}{*}{$\mathrm{T}$} & \multirow[b]{2}{*}{ Sig. } \\
\hline & & B & Std. Error & & & \\
\hline \multirow[t]{4}{*}{1} & "Constant" & 13,166 & 2,796 & & 4,708 &, 000 \\
\hline & $\begin{array}{l}\text { POLA } \\
\text { KEPEMIMPINA } \\
\mathrm{N} \\
\end{array}$ &, 114 & ,091 &, 127 & 1,243 & ,216 \\
\hline & MOTIVASI & ,476 & , 129 & ,461 & 3,698 &, 000 \\
\hline & KOMPENSASI & 139 & 083 &, 167 & 1,681 & 095 \\
\hline
\end{tabular}

a. Dependent Variable: PRODUKTIVITAS

Dari hasil Uji - $\mathrm{t}$ pada table diatas untu variabel pola kepemimpinan dan kompensasi, diperoleh nilai sig $>0,05$, sedangkanvariabel motivasi apabila Sig. 0,00<0,05, maka $\mathrm{H}_{\mathrm{o}}$ diterima dan $\mathrm{H}_{\mathrm{a}}$ ditolak. Nilai Sig. 0.00 hal ini menunjukkan variabel motivasi $<0,05$ maka $\mathrm{H}_{\mathrm{o}}$ dapat diterima yaitu bahwa variabel motivasi secara parsial berpengaruh signifikan terhadap produktivitas kerja karyawan. 
Tabel 4.4

\begin{tabular}{|c|c|c|c|c|c|}
\hline & & $\begin{array}{l}\text { Hasil U } \\
\text { ANOVA }\end{array}$ & & & \\
\hline Model & $\begin{array}{c}\text { Sum of } \\
\text { Squares }\end{array}$ & Df & Mean Square & $\mathrm{F}$ & Sig. \\
\hline 1 Regression & 757,663 & 3 & 252,554 & 43,212 &, $000^{\mathrm{b}}$ \\
\hline Residual & 765,641 & 131 & 5,845 & & \\
\hline Total & 1523,304 & 134 & & & \\
\hline
\end{tabular}

a. Dependent Variable: PRODUKTIFITAS

b. Predictors: (Constant), KOMPENSASI, POLA KEPEMIMPINAN, MOTIVASI

Dari hasil pengujian ini pada tabel 4.4, bahwa pada tingkat $\alpha$ (alfa) 0,05 ataupun 5\% didapatkan sig 0,000 sehingga pada $h_{o}$ berhasil ditolak sedangkan $h_{a}$ tidak ditolak. penolakan $h_{o}$ di buktikan bahwa pada nilai sig. $0,000<0,05$, hal ini menunjukkan bahwa semua variabel berpengaruh secara simultan dan dapat disimpulkan semua variabel pola kepemimpinan, motivasi, dan kompensasi secara simultan berpengaruh signifikan terhadapa produktivitas kerja karyawan.

Tabel 4.5

\section{Output Regresi Linier Berganda}

\begin{tabular}{|c|c|c|c|c|c|c|}
\hline \multicolumn{7}{|c|}{ "Coefficients ${ }^{\mathrm{a} "}$} \\
\hline \multirow{2}{*}{\multicolumn{2}{|c|}{ Model }} & \multicolumn{2}{|c|}{$\begin{array}{l}\text { "Unstandardized } \\
\text { Coefficients" }\end{array}$} & $\begin{array}{l}\text { Standardized } \\
\text { Coefficients }\end{array}$ & \multirow[b]{2}{*}{$\mathrm{t}$} & \multirow[b]{2}{*}{ Sig. } \\
\hline & & $\mathrm{B}$ & Std. Error & Beta & & \\
\hline \multirow[t]{4}{*}{1} & (Constant) & 13,166 & 2,796 & & 4,708 & ,000 \\
\hline & $\begin{array}{l}\text { POLA } \\
\text { KEPEMIMPINAN }\end{array}$ &, 114 & ,091 & ,127 & 1,243 & ,216 \\
\hline & MOTIVASI & ,476 &, 129 & ,461 & 3,698 & ,000 \\
\hline & KOMPENSASI & ,139 & ,083 & 167 & 1,681 & ,095 \\
\hline
\end{tabular}

a. Dependent Variable: PRODUKTIVITAS

Persamaan regresi yang didapat dari kalkulasi tersebut yaitu sebagai berikut:

"Y $=\alpha+b 1 . X 1+b 2 . X 2+b 3 . X 3+e "$

"Y $=13,166+0.114 \mathrm{X} 1+0.476 \mathrm{X} 2+0.139 \mathrm{X} 3 "$

Didapat persamaan regresi, konstanta "13,166" menunjukkan bahwa jika tidak ada variabel pola kepemimpinan $\left(\mathrm{X}_{1}\right)$,motivasi $\left(\mathrm{X}_{2}\right)$ dan kompensasi $\left(\mathrm{X}_{3}\right)$ nilai Produktivitas kerja 13,166 satuan. Dari pernyataan diatas disimpulkan model regresi cocok dipakai untuk memprediksi produktivitas kerja.

Tabel 4.6

Uji Koefisien Determinasi

\section{Summary model}

\begin{tabular}{|c|c|c|c|c|}
\hline Model & $\mathrm{R}$ & R Square & $\begin{array}{l}\text { Adjusted } r \\
\text { square }\end{array}$ & $\begin{array}{l}\text { Std. Error of the } \\
\text { Estimate }\end{array}$ \\
\hline 1 &, $705^{\mathrm{a}}$ & ,497 & ,486 & 2,41756 \\
\hline
\end{tabular}

KEPEMIMPINAN, MOTIVASI

Dalam Tabel 4.6 terlihat besaran nilai $\mathrm{R}_{\text {square }} 0,497$ berasal dari nilai pengkuadratan nilai $\mathrm{R}$ yaitu $(0,705 \times 0,705)$ hal ini menunjukkan bahwa semua variabel secara simultan yaitu pola kepemimpinan, motivasi dan kompensasi mampu menjelaskan variabel produktivitas kerja karyawan 
sebesar $49,7 \%$ dari nilai $\left(\mathrm{R}_{\text {square }} \times 100 \%\right.$ ) selebihnya $50,3 \%$ dapat disebabkan oleh variabel lain yang tidak diteliti seperti kepuasan kerja, pelatihan, konflik, jam kerja dan lain-lain.

\subsection{Kesimpulan}

Dari hasil penelitian dan pembahasan diatas didapat kesimpulan bahwa pola kepemimpinan, motivasi, dan kompensasi dalam PT. So Good Food Unit RTE Boyolali secara simultan berpengaruh terhadap produktivitas kerja karyawan atau pada sumber daya manusianya, hal ini ditunjukan dengan uji analisis regresi berganda secara simultan bahwa nilai signifikasi yaitu $0,000<0,05$ yang menunjukan pola kepemimpinan, motivasi dan kompensasi secara bersamaan dapat berpengaruh secara signifikan terhadap produktivitas kerja karyawan, sebagai tolak ukur perusahaan dalam meningkatkan produktivitas kerja karyawan yaitu dengan memperhatikan pola kepemimpinan, motivasi, dan kompensasi. Sedangkan nilai hasil uji koefisien determinasi $\mathbf{R}_{\text {square }}$ sebesar 0,497 memiliki pengertian bahwapola kepemimpinan, motivasi dan kompensasi secara simultan mampu mempengaruhi variabel produktivitas karyawan sebesar 49,7\% selebihnya 50,3\% dapat disebabkan oleh variabel lain seperti kepuasan kerja, pelatihan, konflik, jam kerja selain variabel - variabel yang diteliti.

Sedangkan hasil analisis regresi berganda dengan uji - $t$ varyabel motivasi dapat menunjukan value sig. 0,00<0,05 yang berarti motivasi dapat berpengaruh signifikan terhadap produktivitas kerja karyawan. Berbanding terbalik dengan penelitian terdahulu yang dilakukan oleh Nurhayati (2016) hasil penelitian menunjukan motivasi kerja memiliki koefisiensi kearah negatif yang di sebabkan semangat kerja karyawan kurang termotivasi sehingga motivasi tidak berdampak secara signifikan terhadap produktivitas kerjakaryawan dengan hasil uji - $\mathrm{t}$ secara parsial menunjukkan bahwa nilai signifikan $0,506>0,05$.

\subsection{Keterbatasan Penelitian}

Penelitian ini mempunyai beberapa kekurangan yaitu, diantaranya sebagai berikut:

Pada riset yang di lakukan bentuknya studi kasus dan hasilnya hanya memunculkan tingkat produktivitas kerja karyawan di PT.So Good Food Unit RTE Boyolali. Keberhasilan dalam melakukan penelitian pada tingkat kualitas dan pengalaman peneliti masih sangat terbatas, karena peneliti pada saat ini masih pada kondisi jenjang studi dan pertama kali melakukan penelitian, dengan demikian peneliti tidak mampu menjelaskan secara rinci dan tepat pada penelitian ini, sehingga adapun kesimpulan yang bisa peneliti uraikan sesuai kondisi yang di dapatkan pada level lapangan.

Dalam hal penelitian ini penulis juga mendapatkan sebuah masalah yaitu mulai dari kemampuan, waktu, biaya yang sangat sangat terbatas pada diri penulis. Serta metode yang dipakai untuk memperoleh data hanya sebatas pada kuesioner yang didapat pada responden serta keterbatasan responden dalam memahami isi pernyataan juga kejujuran responden ketika mengisi kuesioner. Dengan demikian adapaun masalah-masalah yang di dapat kadang tidak sesuai dengan jawaban yang di harapkan maka memengaruhi kualitas peneitian ini.

\subsection{Saran}

Dari hasil penelitian yang telah dilakukan,terdapat beberapa saran yang dapat meningkatkan produktivitas kerja karyawan Pt. So Good Food Unit RTE Boyolali antara lain sbb:

Hasil analisis regresi berganda yang menunjukan pola kepemimpinan motivasi dan kompensasi dengan cara simultan, dan secara parsial akan berpengaruh signifikan kepada produktivitas kerja karyawan, oleh karena itu perusahaan diharapkan dapat terus meningkatkan metode kepemimpinan yang dapat memotivasi karyawan secara berkesinambungan dengan penilaian hasil kerja obyektif serta peningkatan kompensasi guna meningkatkan hasil produktivitas kerja karyawan sehingga tujuan perusahaan dapat tercapai.

Dalam penelitian selanjutnya diharapkan dapat memperluas obyek penelitian, tidak hanya variabel pola kepemimpinan, motivasi, dan kompensasi untuk menambah informasi yang lengkap tentang variabel apa saja yang mempengaruhi produktivitas kerja karyawan. 


\section{DAFTAR PUSTAKA}

K. Amri, U. I. N. Ar-raniry, and B. Aceh, "Pengaruh Perilaku Kepemimpinan dan Motivasi Dalam Meningkatkan Produktivitas kerja”,J. Ekon. Manaj. Dan Bisnis, vol. 3, no. Juni, 2015.

Samsudin, Sadili. “ManajemenSumberDayaManusia”,Bandung :Pustaka Setia, 2010, Hal. 22 - 281."

Hasibuan, Malayu S.P, "ManajemenSumberDayaManusia Perusahaan", Bandung: PT. Bumi Aksa. 2011, Hal. 157."

Sedarmayanti, "Sumber Daya Manusia dan Produktivitas Kerja”. Bandung: “CV Mandar Maju. 2009, Hal. 233."

Notoatmodjo, Soekidjo, "Pengembangan Sumber Daya Manusia”. Jakarta: "Rineka Cipta. 2009, Hal. 142."

Sondang P. Siagian, “Kiat Meningkatkan Produktivitas Kerja”. Jakarta. "PT Rineka Cipta. 2009, Hal. 24."

Arikunto, S., "Prosedur Penelitian Suatu Pendekatan Praktik". Jakarta: "Rineka Cipta, 2010, Hal. 319."

Nurhayati, A.S tentang "Pengaruh Motivasi Kerja dan Gaya Kepemimpinan Terhadap Produktivitas Karyawan Pada Lembaga Keuangan Syariah di Karanggede dan Sekitarnya". Salatiga: "Skripsi IAIN. Vol.3, 2016."

D.Abdullah, "Pengaruh Pengembangan Karir dan Kepuasan Kerja Terhadap Produktivitas Kerja Karyawan PT. Gistex Garment Indonesia Kabupaten Majalengkaz, vol. 3, 2016.” 